\title{
ANALISA EFEKTIFITAS IKLAN TELEVISI PARTAI PERINDO MODEL EPIC (IKLAN DENGAN AKTOR UTAMA KETUA UMUM PARTAI PERINDO)
}

\author{
Nur Siti Khumairoh ${ }^{1}$, Nur Aida ${ }^{1}$ \\ ${ }^{1}$ Sekolah Tinggi Ilmu Ekonomi Gempol Pasuruan \\ E-mail : nur.aidaph@gmail.com \\ http://doi.org/10.21107/pmt.v11i2.4753
}

\begin{abstract}
The aim of this research is for knowing the effectiveness of partai Perindo advertisement by using television media on MNC Group (RCTI, MNCTV, INews and Global TV), with Hary Tanoesoedibyo as an actor and the analyze used EPIC (Empathy, persuasion, impact and communication) model and this research is descriptive research and the population is come from the student of STIE Gempol Pasuruan and it used simple random sampling, and by using Slovin formulation it is gotten the amount of sample is 78. The data collected by giving questioner to the respondent and by using EPIC rate it is showed that empathy rate has 3,32, persuasion rate has 2,79, impact rate has 3,065 and communication rate has 3,28 and all of this value have effectively enough categorized so it must be evaluated and make advertisement strategy as well because it is still not enough for making people to vote this partai. Evaluation should be done as fast as they can because 2018 and 2019 are political year.
\end{abstract}

Key Words : Advertisement, EPIC Model, EPIC rate, Partai Perindo

\section{PENDAHULUAN}

Persaingan diberbagai bidang saat ini yang semakin ketat baik dalam pemasaran produk maupun jasa menuntut dibuatnya strategi pemasaran yang kreatif sehingga menghasilkan iklan yang efektif dan efisien. Dalam kegiatan pemasaran, iklan menjadi bagian dari media komunikasi untuk menyampaikan pesan yang bersifat persuasive dan tentu menarik sehingga menciptakan dan menanamkan persepsi yang baik di benak konsumen terhadap iklan tersebut.

Ada banyak media iklan yang bisa dipakai sebagai alat pemasaran dan salah satu media yang mempunyai cakupan dan menjangkau masyarakat banyak sekaligus menarik adalah iklan melalui media televisi. Dikatakan media televise sebagai media iklan yang mempunyai pengaruh serta bisa menjangkau spectrum konsumen.

Iklan dikatakan efektif bila berhasil mencapai tujuan yang ingin dicapai dan untuk itu iklan harus kreatif, iklan yang berbeda yang tidak biasa-biasa saja (Shimp, 2003). Iklan yang efektif apabila iklan tersebut terpatri secara mendalam dalam benak konsumen dan konsumen mampu mencermatinya dengan sudut pandang yang benar (Durianto et.al, 2003).

Televisi swasta mempunyai peran yang sangat penting dalam pertumbuhan dunia periklanan dan televisi swasta dengan iklannya mampu menggeser posisi iklan media cetak dan radio. Setiap tayangan hiburan, informasi, kuis, film, reality show dan lain-lain tidak bisa dipisahkan dari iklan. Industri periklanan mengalami pertumbuhan yang semakin pesat, semakin kreatif, kegiatan pemasaran lebih terencana untuk memenangkan hati penonoton televisi. Strategi pasarnya melalui proses kreatifitas above the line (media terdepan atas yaitu media masa elektronik dan media masa cetak) diantaranya iklan tv, radio, majalah, surat kabar, tabloid serta internet.

Sebagai pemilik dari empat stasiun televisi yang tergabung dalam MNC Grup, Hary Tanoesoedibyo yang juga pendiri dan Ketua Umum partai Perindo menyadari betul tentang efektifitas iklan melalui media televisi, karena spektrumnya yang luas, sehingga membuat dan menayangkan 
iklan partai Perindo di empat stasiun televise tersebut dengan Ketua Umum sendiri sebagai aktor utama. Didalam iklan partai Perindo ditampilkan kegiatankegiatan partai seperti pembagian gratis gerobak ke pengusaha UMKM beserta kegiatan-kegiatn sosial yang dilakukan dan ada hal yang cukup menarik yaitu diperdengarkannya mars partai Perindo yang enak didengar dan mudah dihapal. Seiring dengan penayangan iklan partai Perindo yang cukup gencar membuat KPI melayangkan sanksi secara tertulis kepada stasiun televisi MNC Group : yakni RCTI, Global TV, MNC TV dan INEWS TV untuk menghentikan siaran iklan Partai Perindo, merujuk pada pasal 36 ayat (4) UndangUndang nomor 32 tahun 2002 tentang Penyiaran, menyebutkan bahwa isi siaran wajib dijaga netralitasnya dan tidak boleh mengutamakan kepentingan golongan tertentu.

Hasil survey yang dilakukan oleh beberapa lembaga survey menunjukkan bahwa partai ini mampu berada di posisi 5 besar, sebuah pencapaian yang sangat membanggakan namun tetap menarik untuk mengetahui efektifitas iklan yang selama ini sudah dilakukan karena biaya untuk penayangan iklan sangat besar sehingga seharusnya juga berdampak besar pula terhadap awareness dan paling penting elektabilitas partai, apalagi tahun 2018 dan 2019 adalah tahun politik. Tujuan penelitian ini adalah untuk mengetahui efektifitas iklan partai Perindo yang tayang di Televisi dengan bintang utama Hary Tanoesoedibyo sebagai ketua umum partai.

Metode penelitian efektifitas iklan sudah banyak dilakukan dalam berbagai jurnal dengan menggunakan beberapa metode pengukuran efektifitas seperti CRI (Customer Response Indeks) DRM (Direct Rating Methode), CDM (Consumer Decision Model) dan EPIC Model (Hasanah et.al, 2015; Hermawan, 2016; Bestriandita dan Widodo, 2017). Pada EPIC Model terdapat empat dimensi yang diukur yaitu $E$ (empathy), P (persuasion), I (Impact), C (communication). Penjelasannya adalah sebagai berikut :
a. Dimensi Empathy (empati): dalam dimensi ini dikonfirmasikan apakah

konsumen atau seseorang menyukai suatu iklan serta menggambarkan bagaimana konsumen melihat hubungan antara suatu iklan dengan pribadi mereka.

b. Dimensi Persuasion (persuasi) : dimensi ini mengkonfirmasi perubahan sikap, kepercayaan dan keinginan berperilaku yang disebabkan suatu komunikasi promosi. Dimensi persuasi menginformasikan apa yang dapat diberikan suatu iklan untuk peningkatan atau penguatan karakter suatu merek, sehingga pemasang iklan memperoleh pemahaman tentang dampak iklan ternhadap keinginan konsumen untuk membeli serta memperoleh gambaran bahwa iklan mampu mengembangkan daya tarik suatu merek.

c. Dimensi Impact (dampak) : dimensi impact menunjukkan apakah suatu merek mampu terlihat menonjol dibandingkan merek lain pada kategori yang sama dan apakah iklan mempunyai kemampuan dalam melibatkan konsumen dalam pesan yang disampaikan.

d. Dimensi Communication (komunikasi) : dalam dimensi ini komunikasi dimaksudkan untuk memberikan informasi tentang kemampuan konsumen dalam mengingat pesan utama yang disampaikan, pemahaman konsumen tentang iklan serta kekuatan pesan yang tertinggal di benak konsumen.

\section{METODOLOGI}

\section{Populasi dan Sample Penelitian}

Populasi adalah wilayah generalisasi yang terdiri dari subjek/objek yang mempunyai kualitas dan karakteristik tertentu seperti yang ditetapkan oleh peneliti untuk dipelajari, kemudian ditarik kesimpulannya (Sugiyono, 2013). Jumlah populasi pada penelitian ini adalah sebanyak 359 mahasiswa STIE Gempol. Adapun penentuan jumlah sampel yang diambil dalam penelitian ini digunakan rumus Slovin yaitu:

$$
\mathrm{n}=\frac{\mathrm{N}}{1+\mathrm{N} \mathrm{e}^{2}}
$$


Keterangan :

n : Ukuran sampel

$\mathrm{N} \quad$ : Ukuran populasi

e $\quad$ : error pada sample

Apabila tingkat toleransi error pada penelitian ini dianggap 10\%, maka jumlah sample penelitian adalah :

$$
\mathrm{n}=\frac{\mathrm{N}}{1+\mathrm{N} \mathrm{e}^{2}}=\frac{359}{1+\mathrm{N}(10 \%)^{2}}=78
$$

Dalam penelitian ini penarikan sampel dilakukan dengan menggunakan tehnik Probability Sampling dengan pengambilan anggota sampel secara Simple Random Sampling yaitu pengambilan sampel dari populasi dilakukan secara acak tanpa memperhatikan strata yang ada dalam populasi dan cara ini dilakukan karena kondisi populasi adalah homogen (Sugiyono, 2013). Jawaban responden akan diberi penilaian mengingat data-data dalam penelitian ini merupakan data kualitatif yang di kuantitatifkan dengan menggunakan skala Likert dengan rentang skala 1-5, kriteria sebagai berikut (1) Sangat Tidak Setuju, (2) Tidak Setuju; (3) Netral; (4) Setuju; (5) Sangat Setuju.

\section{Teknik Analisa Data}

Dalam melakukan analisa efektifitas iklan digunakan Analisis Tabulasi sederhana dan Penghitungan Rata-rata Terbobot dengan langkah-langkah sebagai berikut.

a. Setiap jawaban responden dari pertanyaan dalam kuesioner diberikan bobot dan cara menghitung skor ratarata bobot adalah sebagai berikut :

$$
\overline{\mathrm{X}}=\frac{\sum \text { fi.wi }}{\mathrm{N}}
$$

Keterangan :

$$
\begin{aligned}
\bar{X} & =\text { Rata }- \text { Rata Terbobot } \\
\mathrm{fi} & =\text { Frekuensi } \\
\mathrm{wi} & =\text { Bobot } \\
\mathrm{N} & =\text { jumlah responden }
\end{aligned}
$$

b. Menentukan rentang skala penilaian untuk menentukan posisi tanggapan responden dengan menggunakan nilai skor setiap variable.

Rs $=$ rentang skala
$\mathrm{R}($ bobot $)=$ Bobot max - Bobot min

$\mathrm{M} \quad=$ Banyaknya kategori bobot

Pada penelitian ini digunakan rentang skala 1-5 sehingga didapatkan rentang skala :

$$
\mathrm{Rs}=\frac{5-1}{5}=0,8
$$

Berdasarkan rentang skala tersebut maka dibuat klasifikasi sebagai berikut :

STE : Sangat Tidak Efektif (skala 1,00 1,80)

TE : Tidak Efektif (skala 1,80-2,60)

CE : Cukup Efektif (skala 2,60 - 3,40)

E : Efektif (skala 3,40 - 4,20)

SE : Sangat efektif (skala 4,20 - 5,00)

Setiap dimensi EPIC Model dianalisis secara terpisah dengan memakai skor rata-rata untuk mengetahui efektifitas masing-masing dimensi.

\section{Uii Validitas dan Reliabilitas}

Uji validitas pada penelitian ini digunakan untuk mengetahui kelayakan butir-butir dalam daftar pertanyaan dalam mendefinisikan variable (Sujarweni, 2016). Sekiranya data penelitian didapat dengan pengumpulan jawaban questioner dari responden maka kuestioner harus mampu mengukur apa yang ingin diukur (Riyantoro dan Harmoni 2013). Butir-butir pertanyaan dalam questioner dikatakan valid bila nilai $r$ hitung $>r$ table. Rumus yang digunakan adalah :

$$
r_{x y}=\frac{n \sum X i Y i-\left(\sum X i\right)\left(\sum Y i\right)}{\sqrt{\left(n \sum \mathrm{Xi}^{2}-(\mathrm{Xi})^{2}\right)\left(n \sum \mathrm{Yi}^{2}-\left(\mathrm{Yi}^{2}\right)^{2}\right.}}
$$

Keterangan :

rxy = koefisien korelasi skor item soal

$\mathrm{n} \quad=$ jumlah subyek

$\mathrm{X}=$ skor item

$\mathrm{Y} \quad=$ skor total

Reliabilitas atau kehandalan merupakan ukuran kestabilan dan konsistensi responden dalam menjawab pertanyaan yang disusun dalam questioner dan dikatakan questioner reliable apabila mempunyai nilai Alpha > 0,6 (Sujarweni, 2015). Sebuah jawaban dikatakan reliable apabila pertanyaan yang sama diberikan kepada konsumen pada waktu yang berbeda akan memberikan hasil jawaban yang sama pula. Rumus yang digunakan : 
Keterangan :

$$
\mathrm{r}=\left\lceil\frac{\mathrm{k}}{(\mathrm{k}-1)}\right\rceil\left\lceil 1-\frac{\Sigma \sigma_{\mathrm{b}}^{2}}{\sigma_{\mathrm{t}}^{2}}\right\rceil
$$

$r=$ koefisien reliability instrument

$\mathrm{k}=$ banyaknya butir pertanyaan

$\Sigma \sigma_{\mathrm{b}}^{2}=$ total varian butir

$\sigma_{\mathrm{t}}^{2}=$ total varian

\section{HASIL DAN PEMBAHASAN}

Data pada penelitian didapatkan melalui penyebaran daftar pertanyaan kepada responden, sehingga perlu diadakan uji untuk mengetahui validitas dan reabilitas dari masing-masing butir pertanyaan. Hasil olah data validitas untuk kuisioner menunjukkan bahwa semua pertanyaan adalah valid (rhitung antara 0,832 - 0,930 $>$ rtabel 0,2213). Hasil uji reabilitas menunjukkan bahwa nilai Alpha Cronbach untuk semua 4 dimensi EPIC lebih besar dari $0,6(E=0,861 ; P=0,907 ; I=0,882 ; C$ $=0,855)$ sehingga dikatakan bahwa butirbutir pertanyaan yang digunakan dalam penelitian sudah reliable.

\section{Garis Kontinuum Emphaty}

Dari hasil perhitungan rata-rata untuk dimensi Empathy terlihat bahwa rata-rata untuk pertanyaan yang ke tiga yaitu apakah Anda menyukai iklan partai Perindo mempunyai nilai yang paling kecil yaitu 3,14 yang artinya dimensi ini masuk kategori cukup efektif dengan nilai yang agak mendekati nilai maksimal dari ukuran cukup efektif yaitu 3,4.

Tabel 1. Rata-rata Perhitungan EPIC Iklan TV Perindo

\begin{tabular}{|c|c|c|c|c|c|}
\hline Dimensi & $\begin{array}{c}\text { Butir } \\
\text { pernyataan }\end{array}$ & & $\bar{x}$ & $\begin{array}{l}\text { EPIC } \\
\text { rate }\end{array}$ & Kriteria \\
\hline Emphaty & 1 & $\begin{array}{l}\frac{(1 \times 6)+(2 \times 10)+(3 \times 8)+(4 \times 50)+(5 X 4)}{78} \\
\frac{(1 \times 3)+(2 \times 11)+(3 \times 19)+(4 x 44)+(5 \times 1)}{78} \\
\frac{(1 \times 3)+(2 \times 21)+(3 \times 19)+(4 \times 32)+(5 X 3)}{78}\end{array}$ & $\begin{array}{l}3,46 \\
3,37 \\
3,14\end{array}$ & 3,32 & $\begin{array}{l}\text { Cukup } \\
\text { Efektif }\end{array}$ \\
\hline Persuasi & $\begin{array}{l}1 \\
2\end{array}$ & $\begin{array}{l}\frac{(1 \times 10)+(2 \times 17)+(3 \times 33)+(4 \times 15)+(5 X 3)}{78} \\
\frac{(1 \times 7)+(2 \times 24)+(3 \times 28)+(4 \times 16)+(5 \times 3)}{78}\end{array}$ & $\begin{array}{l}2,79 \\
2,79\end{array}$ & 2,79 & $\begin{array}{l}\text { Cukup } \\
\text { Efektif }\end{array}$ \\
\hline Impact & $\begin{array}{l}1 \\
2\end{array}$ & $\begin{array}{l}\frac{(1 \times 5)+(2 \times 21)+(3 \times 31)+(4 \times 21)+(5 \times 0)}{78} \\
\frac{(1 \times 6)+(2 \times 11)+(3 \times 22)+(4 x 35)+(5 \times 4)}{78}\end{array}$ & $\begin{array}{l}2,87 \\
3,26\end{array}$ & 3,065 & $\begin{array}{l}\text { Cukup } \\
\text { Efektif }\end{array}$ \\
\hline $\begin{array}{l}\text { Commu } \\
\text { nication }\end{array}$ & $\begin{array}{l}1 \\
2 \\
3\end{array}$ & $\begin{array}{l}\frac{(1 \times 1)+(2 \times 15)+(3 \times 31)+(4 \times 27)+(5 X 4)}{78} \\
\frac{(1 \times 4)+(2 \times 13)+(3 \times 23)+(4 \times 3)+(5 \times 35)}{78} \\
\frac{(1 \times 3)+(2 \times 8)+(3 \times 26)+(4 x 38)+(5 \times 3)}{78}\end{array}$ & $\begin{array}{l}3,23 \\
3,23 \\
3,38\end{array}$ & 3,28 & $\begin{array}{l}\text { Cukup } \\
\text { Efektif }\end{array}$ \\
\hline \multicolumn{3}{|c|}{ EPIC rate keseluruhan untuk iklan Televisi Perindo } & 3,11 & & $\begin{array}{l}\text { Cukup } \\
\text { Efektif }\end{array}$ \\
\hline
\end{tabular}




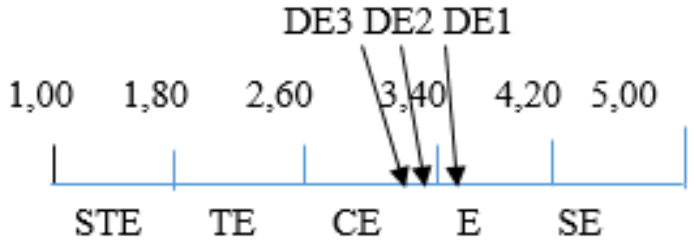

Gambar 1. Garis Kontinuum Emphaty

Tujuan dari pemasangan iklan adalah menciptakan iklan yang efektif bahkan kalau bisa sangat efektif sehingga kalau nilai rata-rata pada garis kontinum cukup efektif maka ini perlu menjadi kajian bagi partai untuk dievaluasi agar masyarakat lebih menyukai iklan yang ditayangkan. Dari ukuran pertanyaan yang kedua yaitu, apakah iklan partai Perindo menarik perhatian, didapat data bahwa nilai ratarata dari pertanyaan ini adalah 3,37 dimana dalam garis kontinum nilai ini masuk dalam kategori cukup efektif dan ada diposisi yang sangat mendekati nilai maksimum dari kategori cukup efektif. Yang menarik dari data responden adalah dari sisi materi iklan, sesuai dengan pertanyaan yang ke tiga yaitu apakah materi iklan menurut Anda bagus, ternyata butir pertanyaan ini masuk dalam kategori efektif yaitu 3,46. Perlu adanya kajian dan evaluasi lebih mendalam terhadap materi iklan untuk mendapatkan materi iklan yang lebih menarik, lebih kreatif sehingga iklan partai Perindo lebih menarik dan lebih disukai pemirsa televisi sehingga nilai dari dimensi Emphaty pada EPIC model berada pada rentang efektif dan sangat efektif.

\section{Garis Kontinuum Persuasion}

Hasil perhitungan rata-rata untuk dimensi persuasion terlihat bahwa rata-rata untuk pertanyaan satu maupun dua nilainya sama yaitu 2,79 . Nilai sebesar ini masuk dikategori cukup efektif namun nilai ini bukan nilai tertinggi dari kategori cukup efektif yaitu 3,4. Tujuan dari pertanyan dimensi persuasi adalah untuk mengukur ketertarikan masyarakat terhadap partai Perindo setelah masyarakat melakukan proses pencarian mendalam tentang partai ini. Tertarik dalam artian membuat masyarakat menjatuhkan pilihan politiknya terhadap partai Perindo setelah mereka melihat tayangan iklan dari partai Perindo.
Apabila nilai rata-rata dari dimensi ini sebesar 2,79 maka partai Perindo harus melakukan evaluasi lagi terhadap konten dari iklan itu sendiri karena bagaimanapun tujuan pemasangan iklan adalah untuk menarik masyarakat dalam menjatuhkan pilihannya pada partai Perindo dalam Pilkada tahun 2018 dan kepentingan pilpres tahun 2019. Kegiatan iklan yang demikian masiv di lakukan di empat stasiun televise selama beberapa bulan, bahkan KPU sampai mengeluarkan teguran, ternyata belum mampu secara maksimal membuat pemirsa televisi jatuh hati pada partai Perindo.

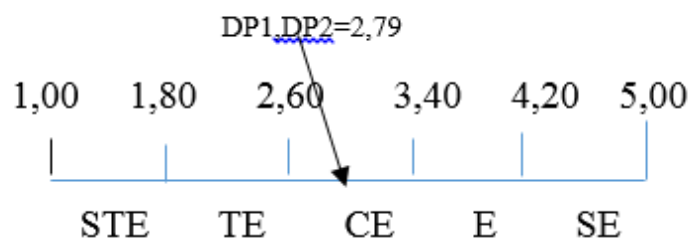

\section{Gambar 2. Garis Kontinuum Persuasion}

\section{Garis Kontinuum Impact}

Nilai rata-rata pertanyaan pertama dari dimensi impact mempunyai nilai 2,87 dan didalam garis kontinum masuk di kategori cukup efektif. Pertanyaan ini dimaksudkan untuk mendorong pemirsa televisi tahu lebih dalam tentang partai Perindo dan dengan nilai rata-rata 2,87 maka perlu dilakukan evaluasi agar iklan di empat stasiun televisi tersebut mampu membuat pemirsa mempunyai pengetahuan yang lebih baik lagi terhadap partai ini.

Nilai untuk pertanyaan kedua yaitu tentang kreatifitas iklan partai Perindo apakah lebih kreatif dibanding iklan partai lain dan jawaban responden sebesar 3,26, berada dalam skala cukup efektif agak mendekati nilai maksimum kriteria cukup efektif, artinya dimata pemirsa iklan televise bahwa iklan partai Perindo ternyata tidak cukup atraktif dibandingkan dengan iklan partai lain. Temuan ini cukup menarik karena secara jelas bahwa kegiatan iklan partai Perindo justru paling menonjol dibandingkan partai lain yang justru jarang dilihat penayangannya di televisi. 


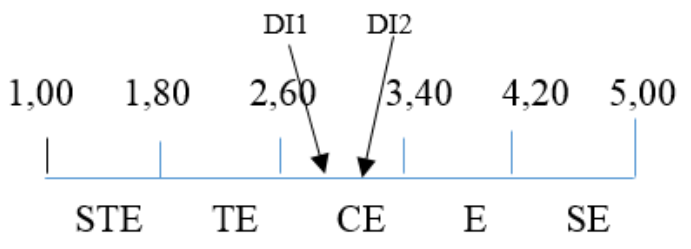

Gambar 3. Garis Kontinuum Impact

\section{Garis Kontinuum Communication}

Dimensi communication menghasilkan nilai rata-rata dari pertanyaan pertama dan kedua adalah sama yaitu 3,23 artinya dari garis kontinum masuk di kategori cukup efektif dan mendekati nilai maksimum dari ukuran cukup efektif. Artinya pemirsa iklan televisi partai Perindo memiliki pemahami terhadap isi dan kejelasan isi dari iklan partai Perindo masih perlu ditingkatkan karena pemahaman terhadap isi atau muatan iklan sangat mempengaruhi keputusan pemirsa dalam menentukan pilihan politiknya. Sementara untuk pertanyaan ketiga yaitu kemampuan partai dalam mengkomunikasikan pesan yang disampaikan mempunyai nilai 3,38 lebih tinggi dari dua pertanyaan yang lain namun tetap masuk di ukuran cukup efektif. Tetap harus dicari upaya untuk menciptakan iklan yang lebih komunikatif dan memudahkan pemirsa dalam memahami isi dari iklan.

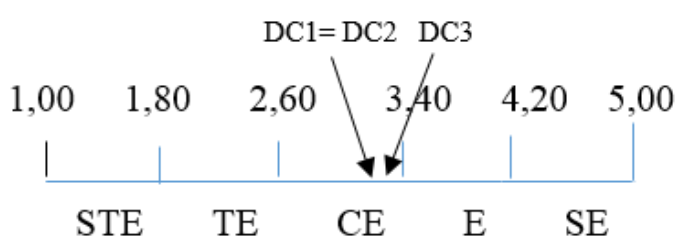

Gambar 4. Garis Kontinuum Communication

Dari perhitungan EPIC rate untuk keempat dimensi semuanya masuk dalam kriteria cukup efektif dan dari nilai EPIC rate menunjukkan bahwa dimensi empathy mempunyai nilai yang paling tinggi yaitu 3,32 diikuti dimensi communication, impact dan yang paling rendah adalah dimensi persuasion. Untuk sebuah iklan di televisi yang memakan biaya yang tidak sedikit apalagi penayangan iklan dilakukan di empat stasiun televise dan hampir setiap hari maka perlu ada pertimbangan kembali tentang strategi iklan yang efektif karena bagaimanapun sumber daya besar yang dikeluarkan mestinya memberikan hasil yang sepadan. Dimensi persuasi, berkaitan dengan ketertarikan pemilih dalam memlih partai Perindo justru mempunyai nilai EPIC rate yang paling rendah dibanding dimensi yang lain dan bukankah tujuan dari iklan yang utama adalah untuk melakukan persuasi agar masyarakat mau diajak memilih partai Perindo tapi dari hasil ratarata justru tujuan persuasi tidak berhasil.

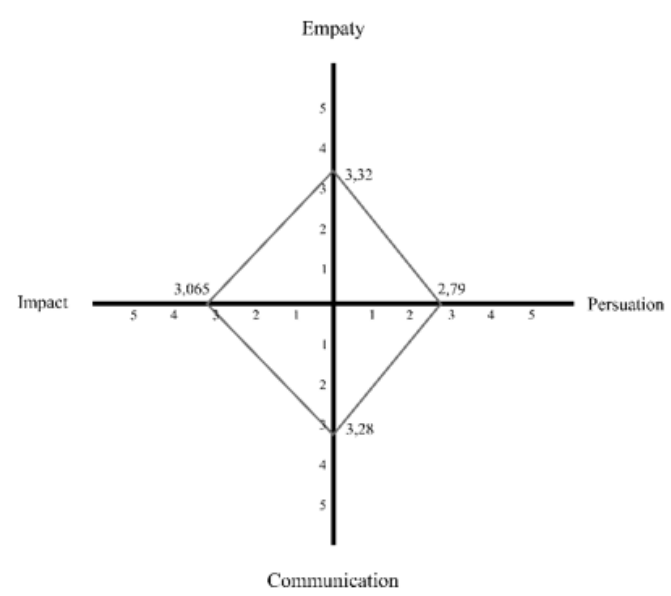

Gambar 5. Hasil EPIC Model

\section{KESIMPULAN}

Perhitungan EPIC rate per dimensi terlihat bahwa semua dimensi pengukuran efektifitas iklan berada pada kriteria cukup efektif dan nilai rata-rata yang paling tinggi adalah dimensi Empathy sedang dimensi yang mempunyai rata-rata paling rendah adalah dimensi persuasion. Artinya dari ke empat dimensi efektifitas iklan semua dimensi memberikan nilai yang masih perlu ditingkatkan karena cukup efektif saja tidak cukup bagi partai untuk meningkatkan elektabilitasnya apalagi pertarungan politik antar partai sangatlah sengit menjelang tahun politik yaitu pilkada tahun 2018 dan pilpres tahun 2019. Memang dari hasil survey yang dilakukan oleh bebrapa lembaga survey menunjukkan bahwa posisi partai ini cukup bagus padahal partai ini termasuk partai baru tapi kalau dilihat lagi masivnya iklan partai ini di stasiun televise dengan biaya iklan yang tidak sedikit maka pencapaian ini masih dirasa 
kurang dan perlu dicari upaya untuk menghasilkan iklan yang lebih menarik dengan konten iklan yang mudah dipahami dan yang terpenting mampu mempengaruhi pemirsa televisl untuk menjatuhkan pilihan politiknya ke partai Perindo.

\section{DAFTAR PUSTAKA}

Bestriandita, D \& Widodo, E. 2017. Analisis Perbandingan Efektivitas Iklan Menggunakan EPIC Model Terhadap Mahasiswa UII Yogyakarta. Prosiding Seminar Nasional Integrasi Matematika Dan Nilai Islami 1 (1):214-20.

Durianto, D., Sugiarto, A.W. Widjaja \& Supratikno, H. 2003. Inovasi Pasar Dengan Iklan Yang Efektif. Jakarta: PT Gramedia Pustaka Utama.

Durianto, Darmadi \& Liana, C. 2003. Inovasi Pasar Dengan Iklan Yang Efektif. Jakarta: PT. Gramedia Pustaka.

Hasanah, N.,Lukito, E.N \& Nugroho, E. 2015. Analisis Efektivitas Iklan Jejaring Sosial Sebagai Media Promosi Menggunakan EPIC Model. Scientific Journal of Informatics 2 (2):99-110.

Kotler, P. 2003. Marketing Insught From $A$ to Z (80 Konsep Yang Harus Dipahami Setiap Manajer). Jakarta: Erlangga.

Maisya, F. 2013. Pengaruh Periklanan, Promosi Penjualan Dan Hubungan Masyarakat Terhadap Keputusan
Menabung Di PT Bank Negara Indonesia, Tbk Cabang Bukittinggi 1:112.

https://doi.org/10.1017/CBO978110741 5324.004.

Mutoharoh., Hasiolan, L.B \& Minarsih, M.M. 2015. Pengaruh Iklan Televisi, Kualitas Produk Dan Gaya Hidup Terhadap Keputusan Pembelian Sabun Kesehatan 'Dettol' Di Swalayan Ada Setiabudi Semarang. Journal of Management 1 (1):1-11.

Riyantoro, B \& Harmoni, A. 2013. Efektivitas Iklan Melalui Jejaring Sosial Sebagai Salah Satu Strategi Pemasaran Kripik Pedas Maichih Dengan Menggunakan Metode EPIC. Proceeding PESAT (Psikologi, Ekonomi, Sastra, Arsitektur \& Teknik Sipil).

http://publication.gunadarma.ac.id/hand le/123456789/6731.

Shimp, T. 2003. Periklanan Promosi Aspek Tambahan Komunikasi Pemasaran Terpadu. Jakarta: Erlangga.

Sugiyono. 2003. Metode Penelitian Bisnis. Bandung: Alfabeta.

_. 2013. Statistika Untuk Penelitian. Alfabeta.

Sujarweni, V. Wiratna. 2015. Statistik Untuk Bisnis \& Ekonomi. Edited by Pertama. Yogyakarta: Pustaka Baru Press. 